\title{
Aplicação de Análises Multivariadas para Determinação da Casta de Abelhas Apis mellifera L. (Africanizadas), Obtidas em Laboratório
}

\section{Izabel Christina da Silva ${ }^{1}$, Dejair Message ${ }^{2}$, Cosme Damião Cruz ${ }^{3}$, Marcos Vinícius Gualberto Barbosa da Silva ${ }^{4}$}

\begin{abstract}
RESUMO - A técnica de criação de larvas de abelhas Apis mellifera em laboratório tem sido utilizada freqüentemente em estudos de desenvolvimento larval, determinação de castas e, mais recentemente, em testes de patogênese. A quantidade e a qualidade do alimento fornecido às larvas em laboratório podem levar à formação de castas diferentes (rainha, operárias ou intercastas). Neste trabalho, crias de abelhas africanizadas foram desenvolvidas a partir de larvas de 18-24 horas de idade até atingir a fase adulta, utilizando-se durante a alimentação, 4, 15, 25, 50 e $70 \mu 1$ de dieta por larva, respectivamente, do primeiro ao quinto dia de alimentação. Para determinar se as abelhas adultas obtidas em laboratório eram pertencentes à casta de operárias, de rainhas ou se eram intermediárias (intercastas), foram comparadas com um controle constituído por operárias e rainhas da mesma origem das operárias desenvolvidas no laboratório, utilizando-se o peso e as medidas dos seguintes caracteres: a) comprimento da cabeça; b) largura da cabeça; c) comprimento do olho composto; d) largura do olho composto; e) comprimento do mesoscuto; f) largura do mesoscuto; g) comprimento da tíbia; h) largura da tíbia. Foram utilizadas a Função Discriminante de Anderson e a técnica de Componentes Principais, de modo a efetuar a discriminação das castas das abelhas adultas obtidas em laboratório em relação àquelas desenvolvidas naturalmente. Entre os caracteres avaliados, os que menos contribuíram para a determinação das castas foram o comprimento do mesoscuto e a largura da cabeça, sendo, portanto, dispensáveis em estudos futuros.
\end{abstract}

Palavras-chave: Apis mellifera, criação de larvas em laboratório, determinação de casta, função discriminante de Anderson, técnica dos componentes principais

\section{Aplication of Multivariate Analysis for Caste Determination in Honeybees Apis mellifera L. (Africanized) Obtained in Laboratory Conditions}

\begin{abstract}
Apis mellifera honeybee brood rearing in laboratory conditions has been frequentely used to search for larval development, caste determination, and more recently for tests of pathogenesis. The amount and quality of food received by larvae during the feeding time can produce different castes (queen, worker or intercaste). In the present work, brood were reared from larvae with 18-24 hours old to adult bee stage and fed 4, 15, 25, 50 e $70 \mu \mathrm{l}$ of a special diet . To determine if the adult bees obtained in laboratory conditions were worker, queen caste or intercaste, they were compared with worker and queen adult bees obtained in natural conditions from the same colony. To discriminate the caste, the weight and the measures of the following characters were used: a) length of head; b) width of head; c) length of compound eyes; d) width of compound eyes ; e) length of mesoscutum; f) width of mesoscutum; g) length of tibia; h) width of tibia. Anderson Function Discriminant and the technique of Main Components were used to allow the discrimination of the caste of Apis mellifera obtained in laboratory conditions compared with worker and queen naturally obtained. Among the studied characteres the ones that fewer contributed to the determination of the castes were the length of the mesoscuto and the width of the head. These characteres can be discarded in future studies.
\end{abstract}

Key Words: Anderson function discriminant, Apis mellifera, brood rearing in laboratory conditions, caste determination, main components technique

\section{Introdução}

As abelhas sociais apresentam a população feminina, em cada colméia, dividida em duas castas (operárias e rainhas) muito diferentes entre si, tanto do ponto de vista morfológico quanto fisiológico, conforme a atividade de cada uma (Campos, 1979). Segundo
Michener (1974), os mecanismos envolvidos na diferenciação das castas apresentam certa generalidade, diferindo apenas em pormenores nas diversas espécies de abelhas. O mecanismo básico de determinação das castas em Apis mellifera é regulado pela quantidade e qualidade do alimento larval (Townsend \& Shuel, 1962; Jay, 1963; Rembold, 1964; Weaver, 1974;

\footnotetext{
${ }_{1}^{1}$ Parte da tese de Mestrado em Entomologia apresentada pelo primeiro autor à UFV. Apoio financeiro: CAPES.

2 Professor do Depto. de Biologia Animal - UFV -Viçosa, MG. E.mail: dmessage@ufv.br

3 Professor do Depto. de Biologia Geral - UFV - Viçosa, MG. E.mail:cdcruz@ufv.br

${ }^{4}$ Pesquisador da EMBRAPA - Gado de Leite. E.mail: marcos@cnpgl.embrapa.br
} 
Beetsma, 1979). Segundo Peng \& Jay (1977), toda larva fêmea com menos de três dias de idade pode se desenvolver como operária ou rainha, dependendo da alimentação fornecida pelas abelhas nutrizes. Esta diferenciação em rainha ou operária depende dos níveis de hormônio juvenil durante o período sensitivo do desenvolvimento larval (Wilde \& Beetsma, 1982). A produção deste hormônio está relacionada à quantidade e à composição do alimento larval (Asencot \& Lensky, 1977).

Quando se realiza a criação de larvas fêmeas de A. mellifera, em laboratório, dependendo da qualidade do alimento fornecido e da quantidade ingerida pela larva, pode-se obter uma rainha, uma operária ou uma intercasta.

Objetivou-se, com este trabalho, avaliar a utilização de análises multivariadas por meio da Função Discriminante de Anderson e da Técnica dos Componentes Principais, para discriminar a casta das abelhas adultas, criadas, desde a fase de larva até imago, em laboratório.

\section{Material e Métodos}

A criação de abelhas em laboratório, a partir de larvas de 18 a 24 horas, até a idade adulta, foi desenvolvida segundo metodologia de Vandenberg \& Shimanuki (1987), modificada por Silva (1995). Para alimentação das larvas, utilizou-se a dieta, segundo Rembold \& Lackner (1981), com modificações nas proporções dos seus nutrientes, conforme a seguinte composição: geléia real (49\%), água $(36,3 \%)$, dfrutose $(6,8 \%)$, d-glicose $(6,8 \%)$ e extrato de levedo $(1,1 \%)$. A dieta oferecida a cada dia do desenvolvimento larval foi: $4 \mu \mathrm{l}$ no primeiro dia; $15 \mu \mathrm{l}$ no segundo; $25 \mu \mathrm{l}$ no terceiro, $50 \mu \mathrm{l}$ no quarto e $70 \mu \mathrm{l}$ no quinto dia.

Para determinar se as abelhas adultas obtidas em laboratório eram pertencentes à casta de operárias, de rainhas ou se eram intermediárias (intercastas), foram comparadas com um controle constituído por operárias e rainhas da mesma origem das larvas desenvolvidas no laboratório. O controle para a casta de operárias foi feito a partir de 10 operárias recémemergidas de cada um dos favos de sete colônias de abelhas A. mellifera (africanizadas) capturadas na região de Viçosa-MG, totalizando-se 70 operárias obtidas em condições naturais. Para se ter a idade das larvas controladas, a rainha de cada colônia foi presa em um favo vazio, por meio de uma tela excluidora de rainha, durante cerca de 12 horas. Após este tempo, foi liberada e os ovos, mapeados. Para o controle da casta de rainhas, foram coletadas 10 rainhas recém-emergidas em minirecrias e obtidas pelo método Doolittle (Corbella, 1981). As abelhas recém-emergidas no laboratório (em um total de 115) e aquelas emergidas em condições naturais (10 rainhas e 70 operárias) foram pesadas e fixadas em Bouin alcoólico, durante 24 horas, sendo mantidas posteriormente em álcool à $70 \%$. As medidas dos caracteres morfológicos foram tomadas, diretamente, em régua micrométrica, acoplada à ocular $(20 \mathrm{x})$ de um microscópio estereoscópico. Para elementos pares, foi tomada a medida daquele situado no lado direito do corpo do inseto. A perna posterior foi retirada do inseto e montada entre lâminas para realização das medidas. Os dados foram processados utilizando-se as medidas em unidades, sem fazer transformação para milímetros. No entanto, com o aumento utilizado, cada unidade da régua micrométrica equivaleu a $0,3 \mathrm{~mm}$.

Os caracteres morfológicos, discriminativos entre rainhas e operárias, foram definidos segundo Campos (1977), Woyke (1978), Bonetti (1982) e Hartfelder \& Engels (1992): a) comprimento da cabeça-medida que corresponde à distância do ocelo mediano até a base do clípeo; b) largura da cabeça - distância máxima entre as tangentes externas aos olhos compostos; c) comprimento do olho composto - distância máxima entre as tangentes paralelas aos bordos superior e inferior do olho composto; d) largura do olho composto - medida da largura máxima do olho composto; e) comprimento do mesoscuto - distância desde o contorno anterior até o limite com o escutelo; f) largura do mesoscuto distância entre as extremidades dos lóbulos pronotais; g) comprimento da tíbia - distância entre a articulação com o fêmur até a extremidade do bordo distal da tíbia posterior; h) largura da tíbia - medida da largura tomada junto ao bordo distal e perpendicular ao comprimento da tíbia posterior.

Para determinar a casta das abelhas desenvolvidas em laboratório, foram utilizados procedimentos de análise multivariada por meio da Função Discriminante de Anderson e da Técnica dos Componentes Principais. Os pormenores da aplicação destas metodologias para determinar a casta de abelhas são apresentados a seguir.

A técnica multivariada denominada Função Discriminante, proposta por Anderson (1958), tem por finalidade classificar um ou mais indivíduos em populações já conhecidas. Neste estudo, considerouse a existência de duas populações, representadas por rainhas e operárias. O problema estatístico consiste em estabelecer a forma de classificar os indivíduos obtidos em laboratório, quando não é possível caracterizá-los 
diretamente, sem que se faça uso de um conjunto de caracteres. Assim, como a determinação de castas não é um caráter simples, julgou-se apropriada a classificação dos indivíduos obtidos em laboratório, por meio de funções discriminantes que considerem, simultaneamente, os caracteres comprimento da cabeça, largura da cabeça, comprimento do olho composto, largura do olho composto, comprimento do mesoscuto, largura do mesoscuto, comprimento da tíbia, largura da tíbia e peso do indivíduo recém-emergido.

Nesta etapa, foram consideradas as informações dos indivíduos, sabidamente, rainhas e operárias:

$\pi_{1}$ : população de rainhas;

$\mathrm{u}_{1}$ : vetor de médias dos $\mathrm{p}$ caracteres avaliados na população $\pi_{1}$;

$\Sigma_{1}$ : matriz de covariância entre os caracteres avaliados na população $\pi_{1}$;

$\pi_{2}$ : população de operárias;

$\mathrm{u}_{2}$ : vetor de médias dos $\mathrm{p}$ caracteres avaliados na população $\pi_{2}$;

$\Sigma_{2}$ : matriz de covariância entre os caracteres avaliados na população $\pi_{2}$; e

$\mathrm{x}$ : vetor representativo dos $\mathrm{p}$ caracteres estudados.

Considerando-se que há homogeneidade das matrizes de covariâncias $\sum_{1}$ e $\sum_{2}$, obtém-se a matriz $\sum$, a partir de $\Sigma_{1}$ e $\Sigma_{2}$, considerando-se os respectivos graus de liberdade. Neste caso, obtém-se:

$$
\begin{aligned}
& \operatorname{Dr}(\mathrm{x})=\ln \left(\mathrm{p}_{1}\right)+\left[\mathrm{x}-(1 / 2) \mathrm{u}_{1}\right]^{\prime} \sum^{-1} \mathrm{u}_{1} \\
& \operatorname{Do}(\mathrm{x})=\ln \left(\mathrm{p}_{2}\right)+\left[\mathrm{x}-(1 / 2) \mathrm{u}_{2}\right]^{\prime} \sum^{-1} \mathrm{u}_{2}
\end{aligned}
$$

Neste estudo, $\operatorname{Dr}(\mathrm{x})$ e $\operatorname{Do}(\mathrm{x})$ são as funções discriminantes que possibilitaram a obtenção de escores para classificação dos indivíduos nas populações $\pi_{1}$ e $\pi_{2}$, consideradas rainhas e operárias, respectivamente, e $\mathrm{p}_{1}$ e $\mathrm{p}_{2}$ (admitidos como iguais a 0,5 ) são as probabilidades de pertencerem às populações $\pi_{1} \mathrm{e} \pi_{2}$, respectivamente.

Pelo critério de classificação de Anderson (1958), classifica-se o i-ésimo indivíduo com vetor de observação $X_{i}$ na população $\pi_{j}(j=1$, ou 2$)$ se, e somente se, $\mathrm{D}\left(\mathrm{x}_{\mathrm{i}}\right)$ for o maior entre os elementos do conjunto $\left[\mathrm{D}_{1}\left(\mathrm{x}_{\mathrm{i}}\right), \mathrm{D}_{2}\left(\mathrm{x}_{\mathrm{i}}\right)\right]$. Portanto, classifica-se determinado indivíduo como operária, se $\operatorname{Do}(\mathrm{x})$ for maior que $\operatorname{Dr}(\mathrm{x})$ e, como rainha, em caso contrário.

Os princípios básicos da técnica dos Componentes Principais são descritos por Mardia et al. (1979), Dunteman (1984) e Cruz \& Regazzi (1994). O objetivo dessa técnica é avaliar a similaridade dos indivíduos, por intermédio de sua dispersão gráfica, utilizando-se os dois primeiros componentes principais como eixo de referência. De acordo com Cruz (1990), cada componente principal é uma combinação linear das variáveis originais. Além disso, os Componentes Principais são independentes entre si e estimados com o propósito de reter, em ordem de estimação, o máximo da informação, em termos de variação total, contida nos dados iniciais.

Para classificar os indivíduos obtidos em laboratório, considerou-se $\mathrm{x}_{\mathrm{ij}} \mathrm{o}$ valor padronizado do j-ésimo caráter $(\mathrm{j}=1,2, \ldots, \mathrm{p})$, avaliado no i-ésimo indivíduo $(i=1,2, \ldots, p)$, e R a matriz de correlações fenotípicas entre os caracteres, com base nos dados originais. A técnica dos Componentes Principais consiste em transformar o conjunto de $\mathrm{p}$ variáveis $\mathrm{x}_{\mathrm{i} 1}, \mathrm{x}_{\mathrm{i} 2}, \ldots, \mathrm{x}_{\mathrm{ip}} \mathrm{em}$ um novo conjunto $y_{i 1}, y_{i 2}, \ldots, y_{i p}$, em que os $y_{i}$ 's são funções lineares dos $\mathrm{x}_{\mathrm{i}}$ 's $\mathrm{e}$ independentes entre si. Assim, as seguintes propriedades são verificadas:

a) se $y_{i j}$ é um componente principal, então:

$$
y_{i j}=a_{1} x_{i 1}+a_{2} x_{i 2}+\ldots a_{p} x_{i p}
$$

b) se $y_{i j}$ '́é outro componente principal, então:

$$
\begin{array}{r}
y_{i j}{ }^{\prime}=b_{1} x_{i 1}+b_{2} x_{i 2}+\ldots b_{p} x_{i p} \\
\sum_{j=1}^{p} a^{2} j=\sum_{j=1}^{p} b^{2} j=1
\end{array}
$$

$\sum_{\mathrm{j}=1}^{p} \mathrm{a}_{\mathrm{j}} \mathrm{b}_{\mathrm{j}}=0$, ou seja, os componentes são nãocorrelacionados; e

c) entre todos os componentes, $\mathrm{y}_{\mathrm{i} 1}$ apresenta a maior variância, $y_{i 2}$ a segunda maior variância e, assim, sucessivamente.

Neste caso, tanto as variáveis das abelhas, obtidas em laboratório, quanto as das operárias e rainhas obtidas em condições naturais, foram utilizadas para a obtenção da matriz de correlação (R). A partir desta matriz, foram obtidos os autovalores, que expressam a quantidade de variância envolvida pelo componente e os respectivos autovetores, cujos elementos são os coeficientes de cada característica estudada. Após a determinação do número de componentes que envolvem um mínimo de $80 \%$ da variação, foram estimados os escores, para cada abelha, relativos aos primeiros Componentes Principais.

Os Componentes Principais foram utilizados também para identificar a disposição das médias das características obtidas em um gráfico bidimensional, utilizando-se a dispersão dos valores das referidas abelhas, em relação aos eixos representativos dos dois primeiros Componentes Principais. A classificação dos adultos obtidos em laboratório foi feita, por meio de exame visual da dispersão de seus escores, em 
relação aos escores obtidos para a média das operárias e para a média das rainhas estudadas.

Todas as análises estatísticas foram realizadas por intermédio do aplicativo computacional GENES (Cruz, 2001).

\section{Resultados e Discussão}

Para identificar as abelhas adultas obtidas em laboratório, quanto ao tipo de casta, foi empregada a técnica multivariada, baseada em função discriminante, que pressupõe uma otimização da identificação quando se considera simultaneamente um conjunto de caracteres tomados em cada abelha. Para obtenção das funções discriminantes, foi necessário o conhecimento prévio das abelhas que, sabidamente, pertenciam a cada uma das castas, nas quais se pretendia alocar as abelhas desconhecidas, obtidas em laboratório.

As funções discriminantes das abelhas rainhas e operárias desenvolvidas em condições naturais, representadas por $\operatorname{Dr}(\mathrm{x})$ e $\operatorname{Do}(\mathrm{x})$, respectivamente, foram obtidas pela técnica multivariada proposta por Anderson (1958) e os resultados são apresentados na Tabela 1. Pode-se observar que cada função é uma combinação linear dos caracteres comprimento da cabeça, largura da cabeça, comprimento do olho composto, largura do olho composto, comprimento do mesoscuto, largura do mesoscuto, comprimento da tíbia, largura da tíbia e peso.

Todas as abelhas adultas obtidas em laboratório foram classificadas corretamente quanto a morfologia, como operárias, pois $\operatorname{Do}(\mathrm{x})$ apresentou maior valor que $\operatorname{Dr}(\mathrm{x})$ em todos os casos analisados.

$\mathrm{Na}$ Tabela 2, constam as estimativas dos autovalores $(\lambda \mathrm{i})$ correspondentes aos Componentes Principais $\left(\mathrm{y}_{\mathrm{is}}\right)$ e os respectivos coeficientes de ponderação (autovetores), associados às variáveis originais.

Os dois primeiros componentes explicam cerca de $61,40 \%$ da variação total $(40,22 \%$ para o primeiro componente e $21,18 \%$ para o segundo). Apesar de os dois primeiros Componentes Principais não envolverem $80 \%$ da variação total, a análise não foi complementada com a dispersão gráfica, em relação ao terceiro e ao quarto componentes, pois, provavelmente isto não mudaria a distribuição dos escores, em relação ao grupo da rainha e da operária. Assim, foi feita a classificação das castas obtidas em laboratório, permitindo-se a transposição de um espaço p-dimensional ( $\mathrm{p}=9$, no caso em questão) para bidimensional.

Na Figura 1, está representada a dispersão gráfica no espaço bidimensional das 115 abelhas operárias, desenvolvidas em laboratório, em relação ao grupo da rainha e da operária, adotando-se o primeiro e o segundo Componentes Principais, correspondentes aos eixos $\mathrm{Y}$ e X, respectivamente.

Na dispersão dos escores, formou-se um grupo em relação à operária-padrão, enquanto a rainha-padrão ficou isolada em relação às demais. Estes resultados são coerentes com os obtidos por Vandenberg \& Shimanuki (1987), que não obtiveram nenhuma rainha ou intercasta, conseguindo, apenas, o desenvolvimento de abelhas operárias.

A importância relativa das medidas dos caracteres morfológicos e do peso para a classificação das castas foi determinada pelos coeficientes e autovalores, apresentados na Tabela 2. Considerando-se que a importância relativa dos Componentes Principais decresce do primeiro para o último, tem-se que os últimos componentes são os responsáveis pela explicação de uma fração mínima da variância total disponível. Assim, o critério adotado na determinação dos caracteres de menor importância consistiu na identificação daqueles que apresentaram maior coeficiente (em valor absoluto), a partir do último componente. Portanto, conclui-se que os caracteres que menos contribuíram para a classificação das castas foram o comprimento do mesoscuto e a largura da cabeça, com maiores pesos em y9 $(-0,779)$ e y8 $(0,801)$,

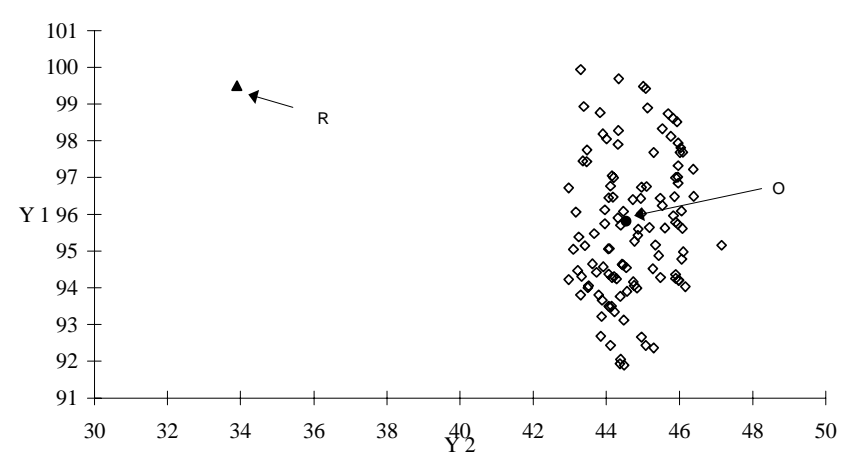

Figura 1 - Dispersão gráfica dos escores, em relação aos eixos representativos dos dois componentes principais ( $\mathrm{Y} 1$ e Y2), de nove caracteres, avaliados em 115 abelhas Apis mellifera (africanizadas), desenvolvidas em laboratório, em rainhas $(R)$ e em operárias $(O)$ desenvolvidas em condições naturais.

Figure 1 - Graphic dispersion of the scores, in relation to the representative axes of the two main components ( $Y 1$ and Y2), of nine characterses, evaluated in 115 bees Apis mellifera (africanizadas), developed in laboratory conditions, in queens $(R)$ and in workers (O) developed in natural conditions. 
Tabela 1 - Coeficiente da Função Discriminante de Anderson das abelhas rainhas e operárias desenvolvidas em condições naturais

Table 1- Anderson Discriminant Function coefficient of the bees queens and workers developed in natural conditions

Característica

Trait
Coeficiente da função para classificação como: Function coeffcient to classification as:

\begin{tabular}{cc}
$\begin{array}{c}\text { Rainha } \\
\text { Queen }\end{array}$ & $\begin{array}{c}\text { Operária } \\
\text { Worker }\end{array}$ \\
\hline$-4255,66$ & $-4616,24$ \\
46,41 & 68,60 \\
87,08 & 98,27 \\
97,17 & 111,64 \\
$-48,10$ & $-47,00$ \\
66,37 & 60,66 \\
$-37,06$ & $-51,77$ \\
25,25 & 6,76 \\
$-48,31$ & $-25,50$ \\
$-2,85$ & $-3,27$
\end{tabular}

Tabela 2 - Estimativas dos autovalores $(\lambda \mathrm{i})$, das contribuições percentuais $(\% \lambda \mathrm{i})$ e dos autovetores obtidos da matriz de correlação, envolvendo os caracteres comprimento da cabeça (CC), largura da cabeça (LC), comprimento do olho composto (CO), largura do olho composto (LO), comprimento do mesoscuto (CM), largura do mesoscuto (LM), comprimento da tíbia (CT), largura da tíbia (LT) e peso (P), avaliados em 115 abelhas adultas desenvolvidas em laboratório, em 70 abelhas operárias desenvolvidas em condições naturais (controle) e em 10 abelhas rainhas desenvolvidas em condições naturais (campo)

Table 2 - Eigenvalues estimates $(\lambda \mathrm{i})$, percentual contribution (\% $\mathrm{i} \mathrm{i})$ and eigenvectors obtained of the correlation matrix, involving the characters length of the head (CC), width of the head (LC), length of the compound eye (CO), width of the compound eye (LO), length of the mesoscutum (CM), width of the mesoscutum (LM), length of the tibia (CT), width of the tibia (LT) and weight $(P)$, evaluated in 115 adult bees, developed in laboratory conditions, in 70 worker bees, developed in natural conditions (controls) and in 10 bees queens, developed in natural conditions (field)

\begin{tabular}{|c|c|c|c|c|c|c|c|c|c|c|c|}
\hline \multirow{2}{*}{$\begin{array}{l}\text { Componente } \\
\text { Component } \\
\text { (y) }\end{array}$} & \multicolumn{2}{|c|}{$\begin{array}{c}\text { Autovalores } \\
\text { Eigenvalues }\end{array}$} & \multicolumn{9}{|c|}{$\begin{array}{l}\text { Autovetores } \\
\text { Eigenvectors }\end{array}$} \\
\hline & $\lambda \mathrm{i}$ & $\% \lambda \mathrm{i}$ & $\mathrm{CC}$ & LC & $\mathrm{CO}$ & LO & $\mathrm{CM}$ & $\mathrm{LM}$ & CT & LT & $\mathrm{P}$ \\
\hline 1 & 3,62 & 40,22 & 0,346 & 0,435 & 0,236 & 0,175 & 0,429 & 0,395 & 0,152 & 0,356 & 0,340 \\
\hline 2 & 1,91 & 21,18 & 0,340 & 0,192 & 0,490 & 0,481 & $-0,291$ & $-0,335$ & $-0,196$ & 0,038 & $-0,375$ \\
\hline 3 & 0,96 & 10,71 & 0,174 & 0,096 & $-0,093$ & $-0,191$ & $-0,227$ & $-0,183$ & 0,852 & 0,213 & $-0,242$ \\
\hline 4 & 0,76 & 8,44 & $-0,063$ & 0,082 & 0,111 & $-0,565$ & $-0,010$ & $-0,128$ & $-0,370$ & 0,679 & $-0,211$ \\
\hline 5 & 0,57 & 6,38 & $-0,610$ & $-0,314$ & 0,446 & 0,256 & 0,168 & 0,256 & 0,236 & 0,219 & $-0,263$ \\
\hline 6 & 0,43 & 4,84 & 0,124 & $-0,092$ & 0,685 & $-0,531$ & 0,008 & $-0,017$ & 0,100 & $-0,420$ & 0,196 \\
\hline 7 & 0,32 & 3,59 & $-0,260$ & $-0,061$ & 0,115 & 0,173 & $-0,213$ & $-0,506$ & 0,079 & 0,273 & 0,710 \\
\hline 8 & 0,26 & 2,93 & $-0,524$ & 0,801 & 0,012 & $-0,076$ & $-0,006$ & $-0,100$ & 0,015 & $-0,247$ & $-0,086$ \\
\hline 9 & 0,15 & 1,70 & $-0,042$ & 0,081 & 0,044 & $-0,017$ & $-0,779$ & 0,592 & $-0,057$ & 0,082 & 0,152 \\
\hline
\end{tabular}


respectivamente, sendo, portanto, dispensáveis em futuros estudos. Caracteres dispensáveis são redundantes, por estarem correlacionados com outros caracteres (Cruz \& Regazzi, 1994).

O descarte do carácter comprimento do mesoscuto $(-0,779)$ é minimizado pela presença da largura do mesoscuto $(0,592)$, assim como o descarte do carácter largura da cabeça $(0,801)$ é minimizado pelo comprimento da cabeça $(-0,524)$ (Tabela 2$)$.

\section{Conclusões}

Os resultados deste trabalho sugerem que a utilização das técnicas multivariadas de Função Discriminante de Anderson e dos Componentes Principais, a partir dos caracteres estudados, é eficiente em discriminar castas de Apis mellifera desenvolvidas em laboratório.

Entre os caracteres analisados (comprimento da cabeça, largura da cabeça, comprimento do olho composto, largura do olho composto, comprimento do mesoscuto, largura do mesoscuto, comprimento da tíbia, largura da tíbia e peso), os que menos contribuíram para a classificação das castas foram o comprimento do mesoscuto e a largura da cabeça, sendo, portanto, dispensáveis em futuros trabalhos.

\section{Agradecimento}

À CAPES, pelo apoio financeiro, sem o qual não seria possível a realização deste trabalho.

\section{Literatura Citada}

ANDERSON, T.W. An introduction to multivariate statistical analysis. New York: John Wiley, 1958. 221p.

ASENCOT, M.; LENSKY, Y. The effect of crystals in stored royal jelly and juvenile hormone on the differentiation of female honeybee (Apis mellifera L.) larvae to queens. In: CONGRESS OF IUSSI, 8., 1977, Wageningen. Proceedings... Wageningen, s.ed., 1977. p.5-10.

BEETSMA, J. The process of queen-worker differentiation in the honey bee. Bee World, v.60, p.24-39, 1979.

BONETTI, A.M. Ação do hormônio juvenil sobre a expressão gênica em Melipona (Hymenoptera, Apidae, Meliponinae). Ribeirão Preto: Universidade de São Paulo, 1982. 141p. Dissertação (Mestrado em Genética) - Universidade de São Paulo, 1982.

CAMPOS, L.A.O. O hormônio juvenil nas abelhas: seu papel na diferenciação das castas e nos aspectos do controle social. Ribeirão Preto: Universidade de São Paulo, 1977.67p. Tese (Doutorado em Genética) - Universidade de São Paulo, 1977.

CAMPOS, L.A.O. Determinação do sexo nas abelhas. XIV. Papel do hormônio juvenil na diferenciação das castas na subfamília Meliponinae (Hymenoptera, Apidae). Revista Brasileira de Biologia, v.39, p.965-71, 1979.
CORBELLA, E. Selecão para aumento de peso de rainhas de Apis mellifera e influência de variáveis climáticas na criação artificial de rainhas. Ribeirão Preto: Universidade de São Paulo, 1981. 110p. Dissertação (Mestrado em Genética) - Universidade de São Paulo, 1981.

CRUZ, C.D. Aplicação de algumas técnicas multivariadas no melhoramento de plantas. Piracicaba: Escola Superior de Agricultura "Luiz de Queiroz", 1990. 188p. Tese (Doutorado em Genética e Melhoramento de Plantas), Escola Superior de Agricultura "Luiz de Queiroz", 1990.

CRUZ, C.D. Programa Genes. Versão windows. Aplicativo computacional em genética e estatística. Viçosa, MG: Universidade Federal de Viçosa, 2001.648p.

CRUZ, C.D.; REGAZZI, A.J. Modelos biométricos aplicados ao melhoramento genético. Viçosa, MG: Universidade Federal de Viçosa, 1994. 390p.

DUNTEMAN, G.H. Introduction to multivariate analysis. Beverly Hills: Sage Publications, 1984. 237p.

HARTFELDER, K.; ENGELS, W. Allometric and multivariate analysis of sex and caste polymorphism in the neotropical stingless bee, Scaptotrigona postica. Insectes Sociaux, v.39, p.251-66, 1992

JAY, S.C. The development of honeybee in their cells. Journal of Apicultural Research, v.2, p.117-34, 1963.

MARDIA, K.V.; KENT, J.T.; BIBBY, J.M. Multivariate analysis. London: Academic Press, 1979. 512p.

MICHENER, C.D. The social behavior of the bees. Cambridge: Havard University Press, 1974. 404p.

PENG, Y-S.C.; JAY, S.C. Larval rearing by worker honey bees lacking their mandibular glands. I. Rearing by small numbers of worker bees. Canadian Entomology, v.109, p.1175-80, 1977.

REMBOLD, H. Die kastenentstehung bei der honigbiene, Apis mellifica L. Naturwissenschaften, v.51, p.49-54, 1964.

REMBOLD, H.; LACKNER, B. Rearing of honeybee larvae in vitro: effect of yeast extract on queen differentiation. Journal of Apicultural Research, v.20, n.3, p.165-171, 1981.

SILVA, I.C. Avaliação de dietas para criação de operárias e zangões de Apis mellifera L. (africanizadas) (Hymenoptera:Apidae) em condições de laboratório. Viçosa, MG: Universidade Federal de Viçosa, 1995. 85p. Dissertação (Mestrado em Entomologia) - Universidade Federal de Viçosa, 1995.

TOWNSEND, G.F.; SHUEL, R.W. Some recent advances in apicultural research. Annual Review of Entomology, v.7, p.481-99, 1962.

VANDENBERG, J.D.; SHIMANUKI, H. Technique for rearing worker honey bees in the laboratory. Journal of Apicultural Research, v.26, p.90-97, 1987.

WEAVER, N. Control of dimorphism in the female honeybee. 2. Methods of rearing larvae in the laboratory and preserving royal jelly. Journal of Apicultural Research, v.13, p.3-14, 1974.

WILDE, J.; BEETSMA, J. The physiology of caste development in social insects. Advances in Insect Physiology, v.16, p.167-246, 1982 .

WOYKE, J. Comparative biometrical investigation on diploid drones of the honeybee. II. The thorax. Journal of Apicultural Research, v.17, p.195-205, 1978. 